\title{
Article \\ Comparison of the Potency of Pterostilbene with NF-kB Inhibitors in Platelet Activation: Mutual Activation by Akt-NF-кB Signaling in Human Platelets
}

\author{
Chih-Wei Hsia 1,+(D, Wei-Chieh Huang ${ }^{1}$, Chih-Hao Yang 1,2,+ , Chih-Hsuan Hsia 1,3, Thanasekaran Jayakumar ${ }^{1}$, \\ Periyakali Saravana Bhavan ${ }^{4}$, Joen-Rong Sheu ${ }^{1,2, *(D)}$ and Kuan-Rau Chiou $1,5,6, *$
}

1 Graduate Institute of Medical Sciences, College of Medicine, Taipei Medical University, Taipei 110, Taiwan; d119106003@tmu.edu.tw (C.-W.H.); m120107013@tmu.edu.tw (W.-C.H.); chyang@tmu.edu.tw (C.-H.Y.); T014913@ms.skh.org.tw (C.-H.H.); jayakumar@tmu.edu.tw (T.J.)

2 Department of Pharmacology, School of Medicine, College of Medicine, Taipei Medical University, Taipei 110, Taiwan

3 Translational Medicine Center, Shin Kong Wu Ho-Su Memorial Hospital, Taipei 111, Taiwan

4 Department of Zoology, School of Life Sciences, Bharathiar University, Coimbatore 641046, Tamil Nadu, India; bhavan@buc.edu.in

5 Department of Internal Medicine, School of Medicine, College of Medicine, Taipei Medical University, Taipei 110, Taiwan

6 Division of Cardiology, Department of Internal Medicine, Shuang Ho Hospital, Taipei Medical University, New Taipei City 235, Taiwan

check for updates

Citation: Hsia, C.-W.; Huang, W.-C.; Yang, C.-H.; Hsia, C.-H.; Jayakumar, T.; Bhavan, P.S.; Sheu, J.-R.; Chiou, K.-R. Comparison of the Potency of Pterostilbene with NF- $\kappa B$ Inhibitors in Platelet Activation: Mutual Activation by Akt-NF-кB Signaling in Human Platelets. Appl. Sci. 2021, 11, 6149. https://doi.org/10.3390/ app11136149

Academic Editor: Qi-Huang Zheng

Received: 18 May 2021

Accepted: 28 June 2021

Published: 2 July 2021

Publisher's Note: MDPI stays neutral with regard to jurisdictional claims in published maps and institutional affiliations.

Copyright: (c) 2021 by the authors. Licensee MDPI, Basel, Switzerland. This article is an open access article distributed under the terms and conditions of the Creative Commons Attribution (CC BY) license (https:/ / creativecommons.org/licenses/by/ $4.0 /)$.
* Correspondence: sheujr@tmu.edu.tw (J.-R.S.); krchiou@tmu.edu.tw (K.-R.C.); Tel.: +886-2-2736-1661-3199 (J.-R.S.)

+ Chih-Wei Hsia and Chih-Hao Yang contributed equally to this work.

\begin{abstract}
Myocardial infarction and cerebral ischemic stroke are prominent causes of death worldwide. Platelets play major roles in these diseases, although they are anucleated cells, but also express the NF- $\kappa$ B. Pterostilbene (PTE) possesses some intriguing pharmacological properties, including the capacity to inhibit platelet activation. We investigated the inhibitory role of PTE in NF- $\mathrm{kB}$-mediated signal events and compared the relative potency with that of classical NF- $\kappa B$ inhibitors. PTE and IкB kinase (IKK) inhibitor, BAY11-7082, and proteasome inhibitor, Ro106-9920, inhibited platelet aggregation; the activity of BAY11-7082 and PTE were similar, but Ro106-9920 was weak in this reaction. PTE and BAY11-7082 diminished NF- $\kappa B$ signaling molecules, including IKK, I $\kappa \mathrm{B} \alpha$, and $\mathrm{p} 65$ phosphorylation, and reversed I $\mathrm{B} \alpha$ degradation. However, Ro106-9920 was only effective in diminishing $\mathrm{p} 65$ phosphorylation and reversing I $\mathrm{K} \mathrm{B} \alpha$ degradation. In investigating the role of Akt and NF- $\mathrm{kB}$ in cell signaling events, MK-2206 (an inhibitor of Akt) markedly abolished IKK and p65 phosphorylation; BAY11-7082 also reduced Akt phosphorylation. PTE exhibited more potent activity in vivo than did BAY11-7082 in acute pulmonary thromboembolism. In conclusion, we identified a distinctive activation pathway of NF- $\mathrm{kB}$ and Akt involved in PTE-mediated antiplatelet aggregation, and PTE demonstrated powerful activity as a prophylactic and as clinical therapy for cardiovascular diseases.
\end{abstract}

Keywords: Akt; arterial thrombosis; human platelets; NF-кB; pterostilbene

\section{Introduction}

Pleiotropic NF-кB normally exists as an inactive cytoplasmic complex; its predominant form is a heterodimer composed of p50 and p65 subunits. These subunits are tightly bound to inhibitors of $\kappa \mathrm{B}(\mathrm{I} \kappa \mathrm{B})$ proteins. NF- $\kappa \mathrm{B}$ activation occurs when $\mathrm{I} \kappa \mathrm{B} \alpha$ is phosphorylated by the I $\mathrm{KB}$ kinase $(\mathrm{IKK})$ complex. The most active subunit of IKK $(\alpha, \beta$, and $\gamma)$ has been

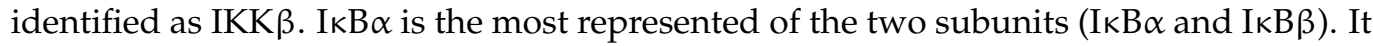
starts dissociating $I \kappa B \alpha$ from NF- $\kappa B$ subunits, and $I \kappa B \alpha$ is then ubiquitinated and rapidly degraded by the proteasome associated with NF- $\mathrm{BB}$ nuclear translocation [1]. NF- $\mathrm{kB}$ is 
considered to be a prototypical proinflammatory pathway that expresses proinflammatoryrelated genes, such as cytokines, chemokines, and adhesion molecules [2]. Therefore, targeting NF- $\mathrm{KB}$ may greatly influence the treatment of various inflammatory diseases.

Platelets represent a critical link between inflammation and thrombosis [3]. Activated platelets stimulate thrombus formation in response to a rupture of atherosclerotic plaque, promoting cardiovascular diseases (CVDs) [4]. Several agonists, such as collagen, thrombin, arachidonic acid, and ADP-induced platelet activation, are associated with the release of various inflammatory mediators, such as P-selectin, interleukin (IL)- $1 \beta$, transforming growth factor- $\beta 1$ (TGF- $\beta 1$ ), matrix metalloproteinases, tumor necrosis factor (TNF)- $\alpha$, and IL-6 [5]. Activated NF- $\mathrm{kB}$ has been identified in human atherosclerotic plaque and has been reported to be enhanced in unstable coronary plaque [6]. Although platelets lack a nucleus, many functional transcription factors, including signal transducer and activator of transcription 3 (STAT3) and NF- $\mathrm{kB}$, are involved in platelet activation [7]. Activation of NF- $\mathrm{kB}$ signaling cascades, such as IKK $\beta$ phosphorylation, ІкB $\alpha$ degradation, and p65 phosphorylation, plays a role in classical agonist-mediated platelet activation [7-9]. However, the detailed mechanisms through which the NF-kB pathway contributes to platelet activation have not been fully elucidated.

The phosphoinositide 3-kinases (PI3Ks) / Akt pathway is activated in response to various stimulating substances, such as growth factors, cytokines, hormones, and extracellular matrix proteins; this pathway regulates a wide spectrum of cellular processes, including cell cycle progression and cell survival. PI3Ks are a family of lipid kinases that are activated in platelets and that regulate platelet activation [10]. Akt is the main downstream effector for PI3Ks, which is phosphorylated by protein kinase $C$ (PKC) and by $\mathrm{Ca}^{2+} /$ calmodulindependent protein kinase and is also amplified by platelet ADP secretion [11,12].

Pterostilbene (PTE; trans-3,5-dimethoxy-4'-hydroxystilbene), a natural stilbenoid occurring in citrus types of fruits, is a dimethylated analog of resveratrol [13]. PTE exhibits numerous notable biological properties, including antiaging, anticancer, antidiabetic, and neuroprotective functions [14,15]. Additionally, PTE inhibited the PDGF-BB-induced cell growth of vascular smooth muscle cells in rats through the inhibition of the Akt-dependent pathway [15]. As described previously [16], PTE (1-5 $\mu \mathrm{M})$ exhibited powerful inhibitory activity in platelet aggregation stimulated by collagen, but not by thrombin, U46619, or arachidonic acid, in human platelets. PTE markedly reduced P-selectin expression, ATP-release, intracellular ([Ca $\left.{ }^{2+}\right]$ i) mobilization, phospholipase C (PLC) $\gamma 2 / \mathrm{PKC}$, and mitogen-activated protein kinase (MAPKs) phosphorylation stimulated by collagen. Further study also demonstrated that PTE strongly interfered with integrin $\alpha_{\mathrm{IIb}} \beta_{3}$-mediated outside-in signaling, such as that involving integrin $\beta_{3}$, Src, and FAK phosphorylation, and reduced the number of adherent platelets and the single platelet spreading area on immobilized fibrinogen as well as the thrombin-stimulated fibrin clot retraction in human platelets [17]. Platelets do not differentiate or proliferate, since they are anucleated cells and, therefore, serve as an ideal model for studying the nongenomic roles of NF- $\mathrm{kB}$. In this study, we investigated the effectiveness and mechanisms of PTE in inhibiting NF- $k B$ activation and its signaling relationship with the PI3Ks/Akt pathway in human platelets. We also compared the relative activity of PTE with classical NF- $\mathrm{kB}$ inhibitors in platelet activation in vitro and acute arterial thrombosis in vivo.

\section{Materials and Methods}

\subsection{Materials}

PTE ( $>98 \%$ ), collagen (type I), bovine serum albumin (BSA), EDTA, paraformaldehyde, and heparin were purchased from Sigma (St. Louis, MO, USA). Anti-IкB $\alpha$ (44D4), antiphospho-IkB $\alpha\left(\mathrm{Ser}^{32} /{ }^{36}\right)(5 \mathrm{~A} 5)$ and phospho-IKK $\alpha / \beta\left(\mathrm{Ser}^{176} /{ }^{180}\right)(16 \mathrm{~A} 6)$ monoclonal antibodies (mAbs), as well as the anti-phospho-NF- $\mathrm{kB}$ p65 $\left(\mathrm{Ser}^{536}\right)$ polyclonal antibody $(\mathrm{pAb})$ were purchased from Cell Signaling (Beverly, MA, USA). Protein assay dye reagent concentrate was purchased from Bio-Rad Laboratories Inc. (Hercules, CA, USA). Anti-phosphoAkt $\left(\mathrm{Ser}^{473}\right) \mathrm{pAb}$ was purchased from BioVision Inc. (Mountain View, CA, USA). The 
6-(phenylsulfinyl)-tetrazolotetrazolo-[1,5-b] (Ro106-992), (E)-3-(4-methylphenylsulfonyl)-2propenenitrile (BAY11-7082), and 8-[4-(1-aminocyclobutyl)phenyl]-9-phenyl-1,2,4-triazolo [3,4-f][1,6]naphthyridin-3(2H)-one, dihydrochloride (MK-2206) were obtained from Cayman (Ann Arbor, MI, USA). $\mathrm{CF}^{\mathrm{TM}} 488 \mathrm{~A}$ Dye and $\mathrm{CF}^{\mathrm{TM}} 405 \mathrm{M}$ Dye were obtained from Biotium (Hayward, CA, USA). The anti- $\alpha$-tubulin $\mathrm{mAb}$ was obtained from NeoMarkers (Fremont, CA, USA), and the Hybond-P polyvinylidene difluoride (PVDF) membrane, enhanced chemiluminescence (ECL) Western blotting detection reagent and analysis system, horseradish peroxidase (HRP)-conjugated donkey anti-rabbit immunoglobulin G (IgG), and sheep anti-mouse IgG were obtained from Amersham (Buckinghamshire, UK). PTE was dissolved in $0.1 \%$ DMSO.

\subsection{Platelet Preparation and Aggregation Study}

This study was approved by the Institutional Review Board of Taipei Medical University (TMU-JIRB-N201812024), and it conformed to the directives of the Helsinki Declaration. In accordance with our previous study, the platelet suspensions were prepared from 30 healthy human blood samples [18] and mixed with an acid-citrate-dextrose solution $(9: 1, v / v / v)$. After centrifugation at $120 \times g$ for $10 \mathrm{~min}$, the supernatant (platelet-rich plasma) was supplemented with EDTA $(2 \mathrm{mM})$ and heparin $(6.4 \mathrm{U} / \mathrm{mL})$, incubated for $5 \mathrm{~min}$, and again centrifuged at $500 \times \mathrm{g}$ for $10 \mathrm{~min}$. The platelet pellet was suspended in $5 \mathrm{~mL}$ of Tyrode's solution, and the mixture was incubated for $10 \mathrm{~min}$ at $37^{\circ} \mathrm{C}$. After centrifugation of the suspension at $500 \times g$ for $10 \mathrm{~min}$, the washing procedure was repeated. The washed platelets were finally suspended in Tyrode's solution containing BSA $(3.5 \mathrm{mg} / \mathrm{mL})$. The platelet count was monitored using a Coulter counter (Beckman Coulter, Miami, FL, USA). The final concentration of $\mathrm{Ca}^{2+}$ was $1 \mathrm{mM}$. Washed human platelets $\left(3.6 \times 10^{8}\right.$ cells $\left./ \mathrm{mL}\right)$ were untreated or pretreated with a solvent control (0.1\% DMSO) or PTE, Ro106-992, and BAY11-7082 at the same concentrations ( 3 and $7 \mu \mathrm{M}$ ) for $3 \mathrm{~min}$ before being stimulated with collagen $(1 \mu \mathrm{g} / \mathrm{mL}$ ) for $6 \mathrm{~min}$. Platelet aggregation was measured using a Lumi-Aggregometer (Payton, Scarborough, Ontario, Canada), and the turbidimetric method was adopted for measurement [18]. The level of platelet aggregation was measured as a percentage of the control (the group treated with Tyrode's solution) in light transmission units.

\subsection{Immunoblotting}

Washed platelets $\left(1.2 \times 10^{9}\right.$ cells $\left./ \mathrm{mL}\right)$ were preincubated with the same concentrations ( 3 and $7 \mu \mathrm{M}$ ) of either PTE, Ro106-992, or BAY11-7082, and a solvent control (0.1\% DMSO) for $3 \mathrm{~min}$, and then collagen was added to activate platelet activation for $5 \mathrm{~min}$. The platelet suspensions were lysed using $200 \mu \mathrm{L}$ of lysis buffer (PMSF $1 \mathrm{mM}$, aprotinin $10 \mu \mathrm{g} / \mathrm{mL}, \mathrm{NaF}$ $10 \mathrm{mM}$, leupeptin $2 \mu \mathrm{g} / \mathrm{mL}$, sodium pyrophosphate $5 \mathrm{mM}$, and sodium orthovanadate $1 \mathrm{mM}$ ) for $1 \mathrm{~h}$. The targeted proteins were electrophoretically separated by a 12\% SDS-PAGE, and the separated proteins were transferred using semidry transfer (Bio-Rad, Hercules, CA, USA) and then blocked using TBST ( $10 \mathrm{mM}$ Tris-base, $0.01 \%$ Tween 20 , and $100 \mathrm{mM} \mathrm{NaCl}$ ) containing $5 \%$ BSA for $1 \mathrm{~h}$. The membranes were incubated with respective primary antibodies (diluted 1:1000 in TBST) and then with HRP-conjugated anti-mouse or anti-rabbit IgG (Amersham, Buckinghamshire, UK; diluted 1:5000 in TBST) for $1 \mathrm{~h}$. The intensity of protein bands was calculated by using a video densitometer and Bioprofil BioLight software, v2000.01 (VilberLourmat, Marne-la-Vallée, France). Relative protein expression was calculated after normalizing the suspensions to the total protein of interest.

\subsection{Confocal Laser Fluorescence Microscopy}

According to the method described by Crosby and Poole, platelets were immunostained to examine the confocal microscopy assay [19]. Briefly, resting or collagen-activated platelets were fixed in $4 \%(v / v)$ paraformaldehyde on poly-L-lysine-coated coverslips for $1 \mathrm{~h}$. The cover slips were then subjected to $0.1 \%$ Triton X-100 and incubated with 5\% BSA for $1 \mathrm{~h}$ and then stained with anti-phospho-NF-KB p65 (Ser $\left.{ }^{536}\right)$ pAb and $\alpha$-tubulin mAb for $24 \mathrm{~h}$ to detect p-p65 and $\alpha$-tubulin. Platelets were further incubated with goat anti-rabbit 
$\mathrm{CF}^{\mathrm{TM}} 488 \mathrm{~A}$ and anti-mouse $\mathrm{CF}^{\mathrm{TM}} 405 \mathrm{M}$ Dyes for $1 \mathrm{~h}$ under a confocal microscope (Leica TCS SP5, Mannheim, Germany) using a 100 $\times$ oil immersion objective.

\subsection{Acute Pulmonary Thromboembolism in Mice}

Acute pulmonary thromboembolism was induced using a previously described method [20]. The Affidavit of Approval of Animal Use Protocol, Taipei Medical University, Taiwan (LAC-2019-0365), followed all the procedures and protocols. Mice were intraperitoneally injected with either 0.1\% DMSO, PTE (2 mg/kg), or BAY11-7082 $(2 \mathrm{mg} / \mathrm{kg}$; all: $50 \mu \mathrm{L}$ ). After $5 \mathrm{~min}, 700 \mathrm{mg} / \mathrm{kg}$ of ADP was injected into each mouse's tail vein. The mortality rate of all groups was observed within 10 min after injection.

\subsection{Data Analysis}

The results are presented as the mean \pm standard error of the mean. Values of $n$ refer to the number of experiments, which were conducted using different blood donors. Variations in the experimental setup were calculated using one-way analysis of variance (ANOVA). Significant differences between the groups were compared using the Student-NewmanKeuls method. $P$ values $<0.05$ indicated statistical significance. Statistical analyses were performed using SAS v9.2 (SAS Inc., Cary, NC, USA).

\section{Results}

3.1. BAY11-7082, Ro106-9920, and PTE Inhibit Collagen-Induced Platelet Aggregation

Both BAY11-7082 and Ro106-9920 belong to a family of NF-KB inhibitors. IKK inhibitor BAY11-7082 has several pharmacological properties that include anticancer, neuroprotective, and anti-inflammatory [21] and Ro106-9920 is an inhibitor of the ubiquitination of activated I $\mathrm{B} \alpha \alpha[22,23]$. In the present study, BAY11-7082 and Ro106-9920 or PTE concentration-dependently inhibited collagen $(1 \mu \mathrm{g} / \mathrm{mL})$-stimulated platelet aggregation in human platelets at equal concentrations ( 3 and $7 \mu \mathrm{M}$; Figure 1A-C). BAY11-7082 exhibited inhibitory activity similar to that of PTE, whereas Ro106-9920 exhibited less activity on a molar level (Figure 1D). Hence, we used BAY11-7082 to examine the signal association between NF-KB and the PI3K/Akt pathway in PTE-mediated antiplatelet activity.

$\mathbf{A}$

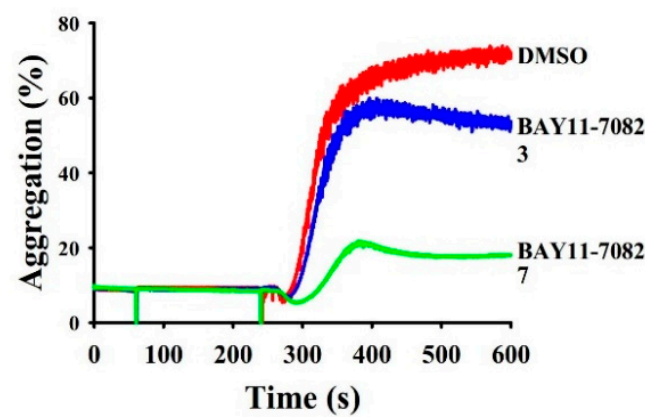

Figure 1. Conts.

\section{B}

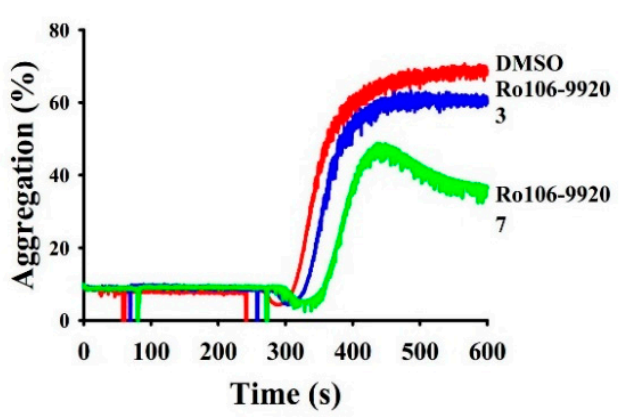




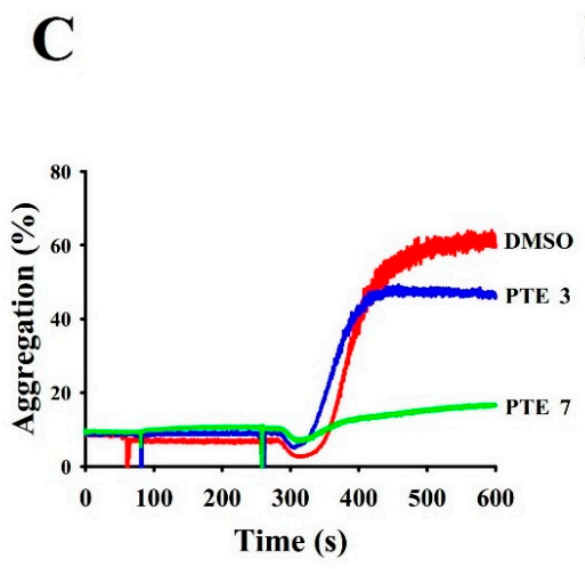

\section{D}

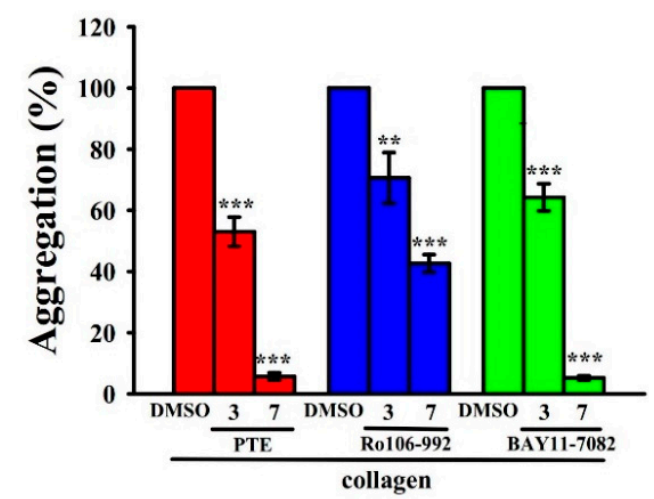

Figure 1. Regulatory activity of NF- $\mathrm{kB}$ inhibitors and pterostilbene (PTE) in collagen-stimulated platelet aggregation in human platelets. Washed platelets $\left(3.6 \times 10^{8}\right.$ cells $\left./ \mathrm{mL}\right)$ were preincubated with (A) BAY11-7082 (3 and $7 \mu \mathrm{M})$, (B) Ro106-9920 (3 and $7 \mu \mathrm{M})$, or (C) PTE (3 and $7 \mu \mathrm{M})$, followed by collagen treatment $(1 \mu \mathrm{g} / \mathrm{mL})$ to trigger platelet aggregation. The corresponding statistical data are displayed in (D). Data are presented as mean \pm standard error of the mean $(n=4){ }^{* *} p<0.01$ and ${ }^{* * *} p<0.001$, compared with the $0.1 \%$ DMSO-treated group.

\subsection{PTE Suppressed NF- $\kappa B$ Signals in Collagen-Activated Platelets}

NF- $\kappa B$, an inactive heterodimer, consists of p50 and p65 subunits that are strongly bound with its inhibitory protein IкB [24]. Figure 2 indicates that IKK, IкB $\alpha$, and p65 phosphorylation and $\mathrm{I} \kappa \mathrm{B} \alpha$ degradation expressively augmented in collagen $(1 \mu \mathrm{g} / \mathrm{mL})$ induced platelets, and PTE ( 3 and $7 \mu \mathrm{M})$ concentration dependently reversed all these reactions. Figure 2 displays the statistical data below panels of each immunoblotting profile. These results suggest that the inhibition of NF- $\mathrm{BB}$ signaling plays an influential role in PTE-mediated antiplatelet activity.

\section{A}
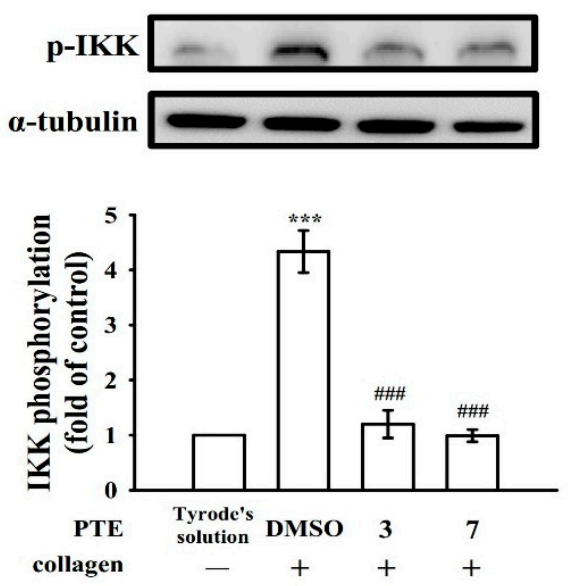

B
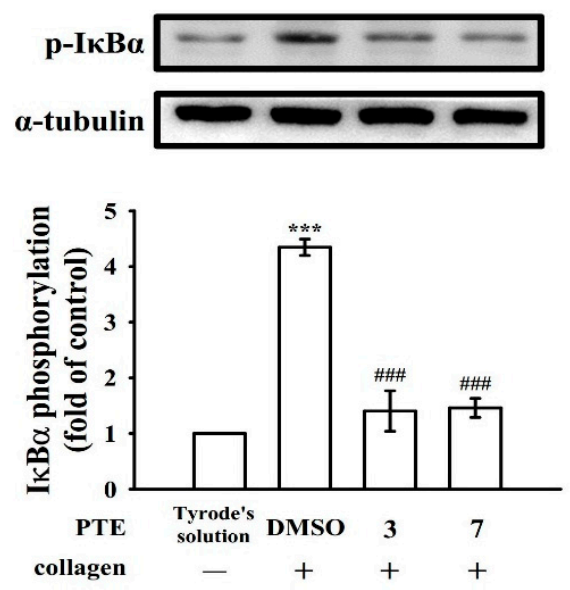

Figure 2. Conts. 
C
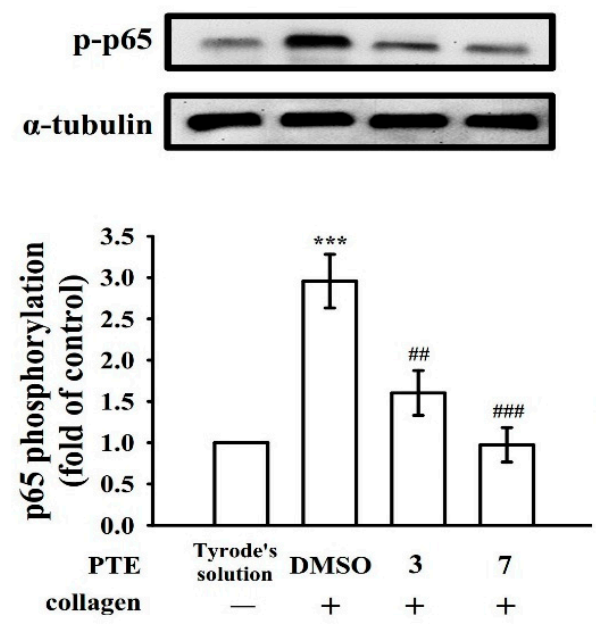

D
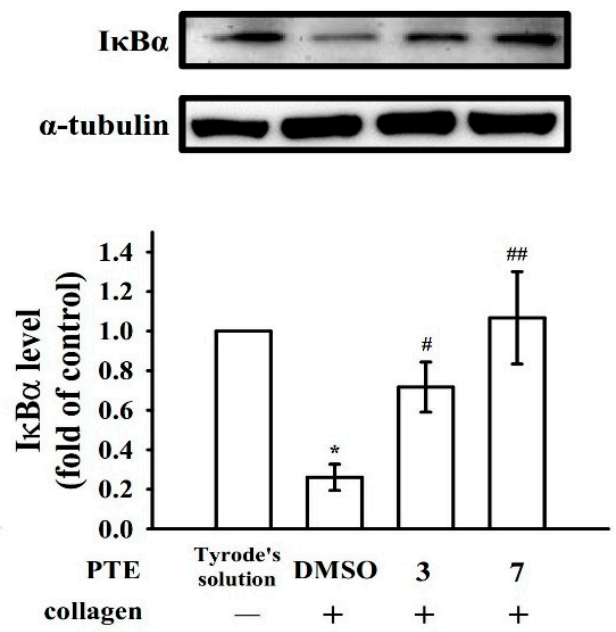

Figure 2. The influence of NF- $\mathrm{kB}$ activation by pterostilbene (PTE) in platelets. Washed platelets $\left(1.2 \times 10^{9}\right.$ cells $\left./ \mathrm{mL}\right)$ were preincubated with PTE $(3$ and $7 \mu \mathrm{M})$ or a solvent control $(0.1 \% \mathrm{DMSO})$, followed by collagen treatment $(1 \mu \mathrm{g} / \mathrm{mL})$ to trigger $(\mathbf{A}) \mathrm{IKK},(\mathbf{B}) \mathrm{I} \kappa \mathrm{B} \alpha$, and $(\mathbf{C})$ p65 phosphorylation or (D) $\mathrm{I} \kappa \mathrm{B} \alpha$ degradation for immunoblotting study. Data are presented as mean \pm standard error of the mean $(n=4){ }^{*} p<0.05$ and ${ }^{* * *} p<0.001$, compared with the resting control (group treated with Tyrode's solution); ${ }^{\prime} p<0.05,{ }^{\# \#} p<0.01$, and ${ }^{\# \#} p<0.001$, compared with the $0.1 \%$ DMSO-treated group.

\subsection{Relative Activity of BAY11-7082 and Ro106-9920 in NF-kB Activation}

BAY11-7082 and Ro106-9920's effectiveness in reducing NF- $\kappa$ B activation were further compared. As Figures 3 and 4 illustrate, BAY11-7082 ( 3 and $7 \mu \mathrm{M}$ ) exhibited potent activity in inhibiting IKK, I $\mathrm{I} B \alpha$, and p65 phosphorylation and reversing $\mathrm{I} \kappa \mathrm{B} \alpha$ degradation for collagen-stimulated platelets. Nevertheless, Ro106-9920 (3 and $7 \mu \mathrm{M})$ only affected p65 phosphorylation and I $\mathrm{kB} \alpha$ degradation (Figure $4 \mathrm{C}, \mathrm{D}$ ) and had no effect on IKK and IkB $\alpha$ phosphorylation (Figure 4A,B).

A
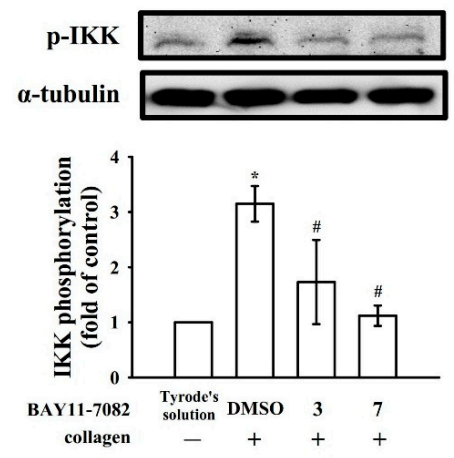

B
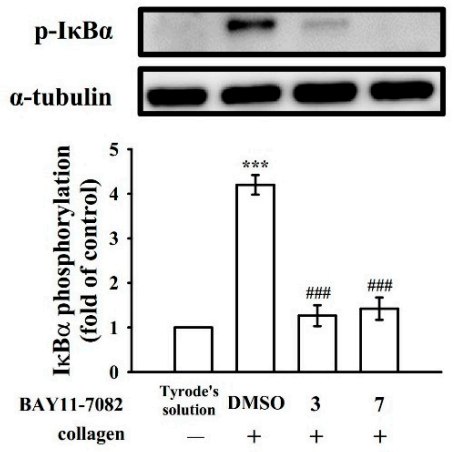

Figure 3. Conts. 
C
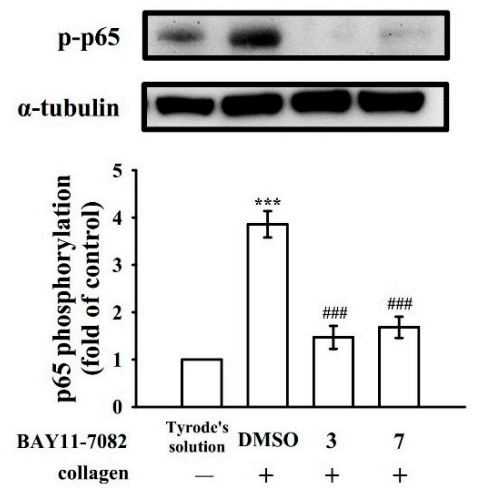

D

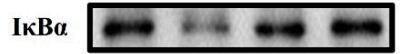

$\alpha$-tubulin $-\infty-\infty$

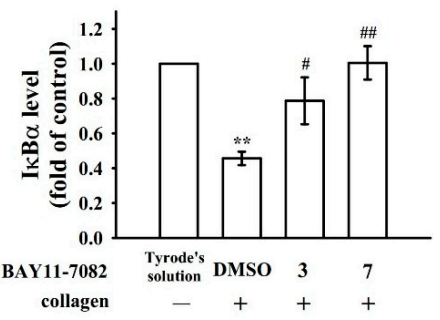

Figure 3. The role of BAY11-7082 on NF- $\mathrm{BB}$ activation in platelets. Washed platelets $\left(1.2 \times 10^{9} \mathrm{cells} / \mathrm{mL}\right)$ were preincubated with BAY11-7082 (3 and $7 \mu \mathrm{M})$ or a solvent control (0.1\% DMSO), followed by collagen treatment $(1 \mu \mathrm{g} / \mathrm{mL})$ to trigger (A) IKK, (B) IKB $\alpha$, and (C) p65 phosphorylation or (D) IKB $\alpha$ degradation for immunoblotting study. Data are presented as mean \pm standard error of the mean $(n=4) .{ }^{*} p<0.05$, ** $p<0.01$, and *** $p<0.001$, compared with the resting control (group treated with Tyrode's solution); \# $p<0.05,{ }^{\# \#} p<0.01$, and ${ }^{\# \#} p<0.001$, compared with the $0.1 \%$ DMSO-treated group.

A
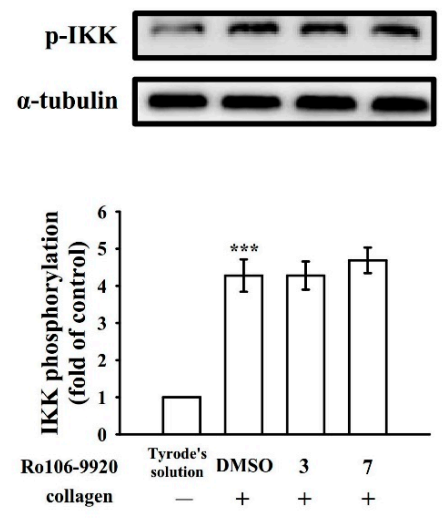

C
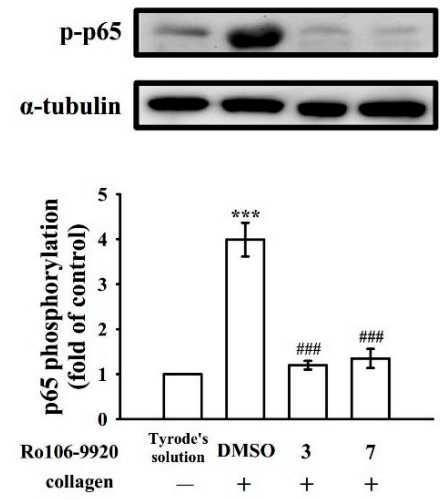

B
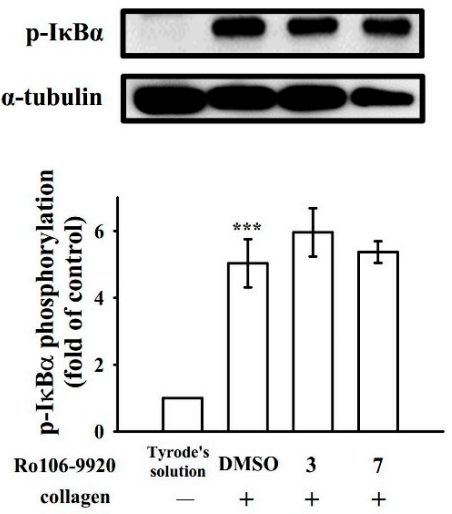

D
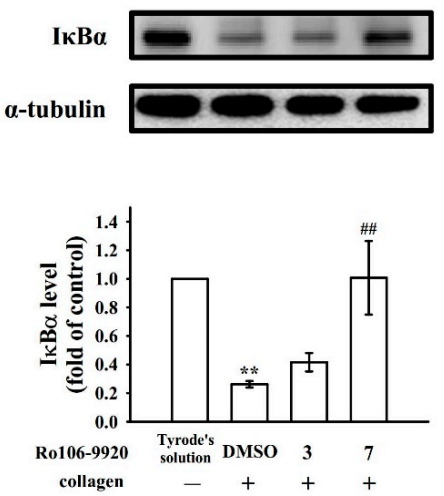

Figure 4. Effect of NF- $\mathrm{KB}$ activation by Ro106-9920 in platelets. Washed platelets $\left(1.2 \times 10^{9}\right.$ cells $\left./ \mathrm{mL}\right)$ were preincubated with Ro106-9920 (3 and $7 \mu \mathrm{M})$ or a solvent control (0.1\% DMSO), followed by collagen treatment $(1 \mu \mathrm{g} / \mathrm{mL})$ to trigger (A) IKK, (B) I $\mathrm{KB} \alpha$, and (C) p65 phosphorylation or (D) I $\mathrm{B}$ B $\alpha$ degradation for immunoblotting study. Data are presented as mean \pm standard error of the mean $(n=4) .{ }^{* *} p<0.01$, and ${ }^{* * *} p<0.001$, compared with the resting control (group treated with Tyrode's solution); ${ }^{\# \#} p<0.01$, and ${ }^{\# \# \#} p<0.001$, compared with the $0.1 \%$ DMSO-treated group. 
3.4. Effect of PTE, BAY11-7082, and Ro106-9920 in Immunostaining of p65 Phosphorylation by Confocal Microscopy

As Figure 5 illustrates, the influence of PTE, BAY11-7082, and Ro106-9920 in NF$\mathrm{\kappa B}$ activation was further confirmed by using confocal laser fluorescence microscopy to compare the direct immunostaining results of anti-p-p65 mAb (green fluorescence) with those of $\alpha$-tubulin (blue fluorescence) in resting or collagen-activated platelets. Collagen $(1 \mu \mathrm{g} / \mathrm{mL})$ increased $\mathrm{p}-\mathrm{p} 65$ fluorescence intensity compared with the resting group. The intensity of p-p65 was significantly reduced in PTE-, BAY11-7082-, or Ro106-9920-treated groups compared with the resting control (Figure 5). However, $\alpha$-tubulin intensity did not alter among the groups (Figure 5).

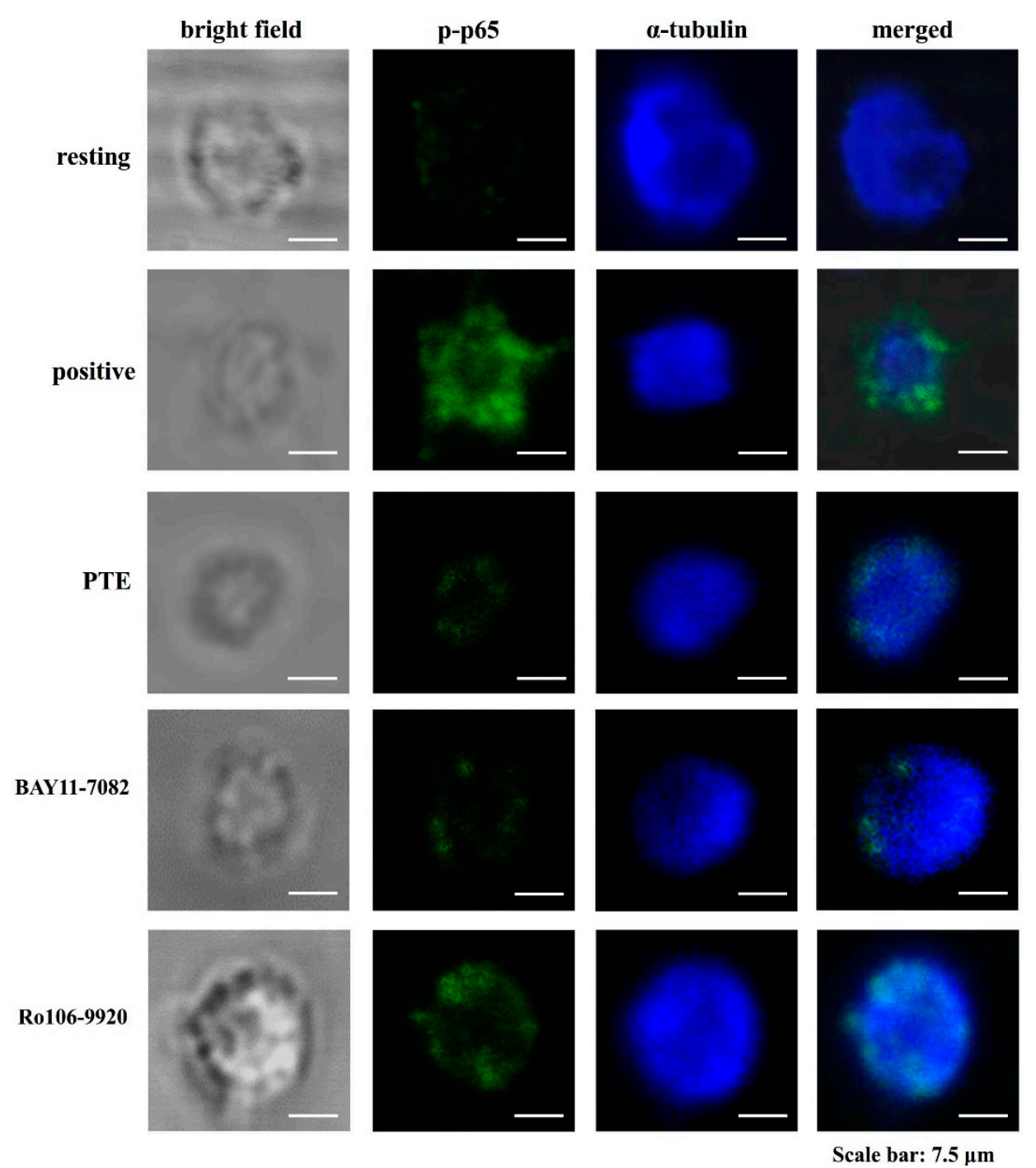

Figure 5. Activity of pterostilbene (PTE), BAY11-7082, and Ro106-9920 in regulating collagenstimulated p65 phosphorylation in human platelets as determined through a confocal laser fluorescence study. Washed platelets $\left(1.2 \times 10^{9}\right.$ cells $\left./ \mathrm{mL}\right)$ were preincubated with PTE $(7 \mu \mathrm{M})$, BAY11$7082(7 \mu \mathrm{M})$, or Ro106-9920 $(7 \mu \mathrm{M})$, followed by collagen treatment $(1 \mu \mathrm{g} / \mathrm{mL})$ to trigger platelet aggregation. The confocal images of p-p65 (green fluorescence) and $\alpha$-tubulin (blue fluorescence) were observed by using goat anti-rabbit $\mathrm{CF}^{\mathrm{TM}} 488 \mathrm{~A}$ Dye and goat anti-mouse $\mathrm{CF}^{\mathrm{TM}} 405 \mathrm{M}$ Dye, respectively, as described in the Section 2. The profiles represent four similar studies. Bar: $7.5 \mu \mathrm{m}$. 


\subsection{Signal Crosstalk Between Akt and NF- $\kappa B$}

Akt, referred to as protein kinase B, can be activated by several platelet agonists that regulate platelet activation and hemostasis [25]. As described previously [16], PTE markedly diminishes the phosphorylation of Akt stimulated by collagen. In the present study, we further investigated cellular signaling events between PI3K-Akt and NF- $\mathrm{kB}$. When platelet suspensions were treated with PTE $(7 \mu \mathrm{M})$, BAY11-7082 $(7 \mu \mathrm{M})$, and MK-2206 $(10 \mu \mathrm{M}$; an inhibitor of Akt), all these reagents nearly abolished collagen-stimulated IKK, p-p65, and Akt phosphorylation (Figure 6A-C). The confocal study also provided evidence that demonstrated MK-2206 diminished p-p65 fluorescence (Figure 6D), convincingly suggesting that Akt and NF- $\mathrm{KB}$ activated each other during platelet activation and are also involved in PTE-mediated antiplatelet activation.

A
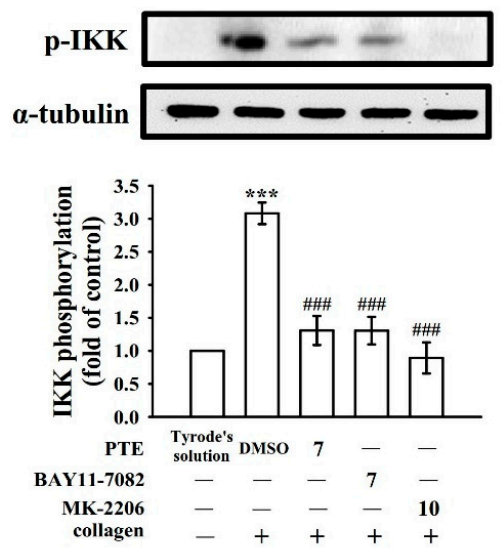

C
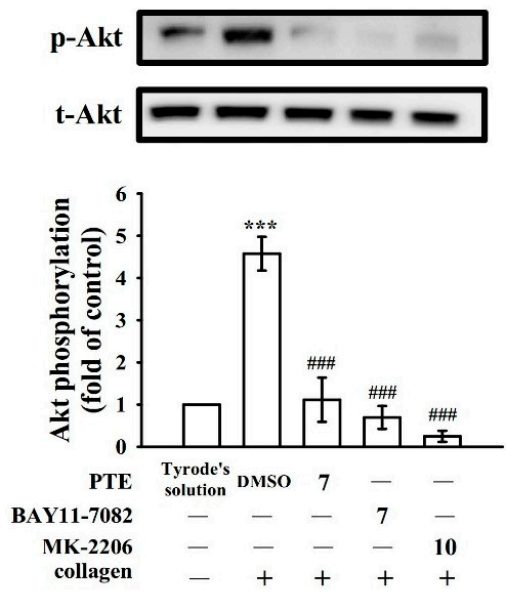

B
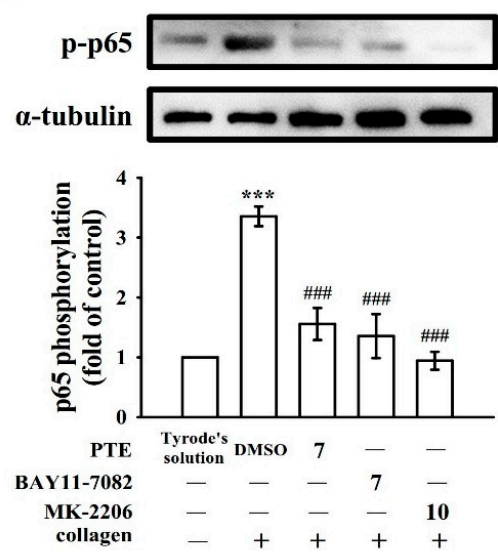

D

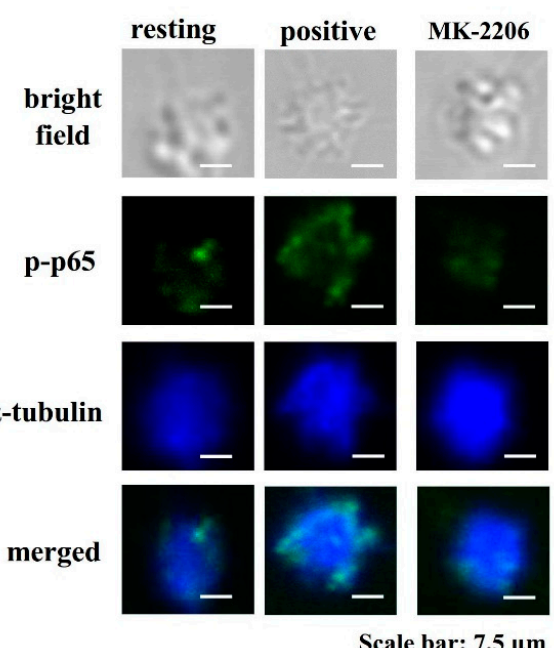

Figure 6. Regulatory profiles of pterostilbene (PTE), BAY11-7082, and MK-2206 on NF-kB and Akt activation in human platelets. Washed platelets $\left(1.2 \times 10^{9}\right.$ cells $\left./ \mathrm{mL}\right)$ were preincubated with 0.1\% DMSO, PTE $(7 \mu \mathrm{M})$, BAY11-7082 $(7 \mu \mathrm{M})$, or MK-2206 $(10 \mu \mathrm{M})$ and then treated with collagen $(1 \mu \mathrm{g} / \mathrm{mL})$ to trigger (A) IKK, (B) p65, and (C) Akt phosphorylation. Data are presented as mean \pm standard error of the mean $(n=4)$. ${ }^{* * *} p<0.001$, compared with the resting control (group treated with Tyrode's solution); ${ }^{\# \#} p<0.001$, compared with the $0.1 \%$ DMSO-treated group. (D) For further study, washed platelets $\left(1.2 \times 10^{9}\right.$ cells $\left./ \mathrm{mL}\right)$ were preincubated with MK-2206 $(10 \mu \mathrm{M})$, followed by collagen treatment $(1 \mu \mathrm{g} / \mathrm{mL})$ to trigger platelet aggregation. The confocal images of p-p65 (green fluorescence) and $\alpha$-tubulin (blue fluorescence) were observed by using goat anti-rabbit $\mathrm{CF}^{\mathrm{TM}}$ 488A Dye and goat anti-mouse $\mathrm{CF}^{\mathrm{TM}} 405 \mathrm{M}$ Dye, respectively, as described in the Section 2. The profiles represent four similar studies. Bar: $7.5 \mu \mathrm{m}$. 


\subsection{Comparison of the Potency of PTE and BAY11-7082 in Reducing Acute Pulmonary Thrombosis Mortality}

The therapeutic potency of PTE as compared with BAY11-7082 was evaluated in terms of preventing mice mortality caused by ADP-induced acute pulmonary embolism, as presented in Table 1 . The data obviously showed that PTE at $2 \mathrm{mg} / \mathrm{kg}$ expressively reduced the ADP $(700 \mathrm{mg} / \mathrm{kg}$ )-induced mortality rate from $100 \%$ (12 dead, $n=12 ; 0.1 \%$ DMSO control) to $33 \%$ (four dead, $n=12)$. Furthermore, BAY11-7082 $(2 \mathrm{mg} / \mathrm{kg}$ ) reduced the mortality to $67 \%$ (eight dead, $n=12$ ). Therefore, the potency of PTE is approximately two times greater than that of BAY11-7082; these data clearly indicated that PTE is a potentially potent reagent for thromboembolic diseases.

Table 1. Effect of pterostilbene (PTE) and BAY11-7082 on mortality of acute pulmonary thrombosis caused by intravenous injection of ADP in experimental mice.

\begin{tabular}{lccc}
\hline & Total Number (n) & Number of Deaths (n) & Mortality (\%) \\
\hline ADP (700 mg/kg) & & & \\
+ solvent control $(0.1 \% \mathrm{DMSO})$ & 12 & 12 & 100 \\
+ PTE $(2 \mathrm{mg} / \mathrm{kg})$ & 12 & 4 & 33 \\
+ BAY11-7082 $(2 \mathrm{mg} / \mathrm{kg})$ & 12 & 8 & 67 \\
\hline
\end{tabular}

\section{Discussion}

PTE is a naturally occurring dimethylether and an analog of resveratrol; it has stronger metabolic activity than resveratrol due to single hydroxyl group attachment, but resveratrol has three hydroxyl groups. Resveratrol, a polyphenol compound, was reported to aid the prevention of atherosclerosis and heart diseases [26]. However, resveratrol possesses low bioavailability with rapid first-pass metabolism [26]. PTE has been recommended because its chemical structure leads to increased lipophilicity and membrane permeability, ensuing in better pharmacokinetics than those of resveratrol [27]. Therefore, PTE's plasma concentration and bioavailability are much better than those of resveratrol under equimolar doses, unrelated to the dose and route of administration. The pharmacokinetics of PTE in rats have been reported; under the daily oral dosage of $56 \mathrm{mg} / \mathrm{kg}$ for 14 days, the rats' blood concentration was approximately $2550 \mathrm{ng} / \mathrm{mL}(\sim 10 \mu \mathrm{M})$ [28], indicating that the concentration used in the antiplatelet was reasonable after dietary intake. Even if regular PTE obtained from natural sources would be insufficient for achieving the plasma concentration required to inhibit in vivo platelet activation, long-term intake of a sufficient quantity of PTE is ideally suited for preventing CVDs. Thus, PTE is a potentially innovative candidate for treating arterial thrombosis-related diseases for humans.

The function of NF- KB is well studied in nucleated cells. Stimulation by cytokines, ultraviolet radiation, free radicals, or viral infection can trigger NF- $\mathrm{kB}$ activation, resulting in inflammation and impairing cell survival, differentiation, and proliferation [24]. Hence, the inhibition of NF- $\mathrm{KB}$ would be an ideal target for the treatment of inflammatory diseases or cancers. In the present study, PTE had good inhibitory potency in collagen-stimulated NF- $\kappa B$ activation (IKK, I $\kappa B \alpha$, and p65 phosphorylation, as well as I $\kappa \mathrm{B} \alpha$ degradation) in human platelets, so that NF- $\mathrm{KB}$ signaling plays a key role in PTE-mediated antiplatelet activity. Platelets, despite being anucleated cells, can express transcription factors [29,30], which suggests that NF- $\mathrm{KB}$ in platelets is involved in roles apart from those involving genomic functions. In the current study, the existence of NF- $\mathrm{kB}$ (p-p65) in human platelets was observed through confocal microscopy, exhibiting novel cooperative activity with other signaling actors (i.e., the PI3K-Akt pathway) after platelet activation. Additionally, NF- $\mathrm{kB}$ inhibitors have been reported to diminish platelet activation [31]. In this study, BAY11-7082 showed more potent activity than Ro106-9920 in inhibiting platelet activation, providing convincing evidence that NF- $\mathrm{KB}$ influences platelet activation. 
Studying the function of Akt in platelets is predominantly achieved by using mice models and deleting individual Akt isoforms. Among the generated genetically modified mice, only Akt1-deficient mice have exhibited a significant defect in response to collagen. Specifically, Akt1 deficiency reduced platelet aggregation and prolonged tail bleeding duration, suggesting that Akt1 is the major isoform preferentially activated during collagen-mediated platelet activation and contributes more directly to hemostasis $[32,33]$. By contrast, deletion of Akt2 results in a normal response to collagen stimulation [32]. Furthermore, Akt3-deficient mice respond normally to collagen stimulation and exhibit a decreased response to thrombin and $\mathrm{TXA}_{2}$ [34]. However, the role of Akt3 in platelet activation is controversial, as Moore et al. [35] reported that although Akt3 is expressed in platelets, the researchers were unable to detect activation of Akt3 after agonist stimulation. Pharmacological inhibitors for each isoform have not yet been developed; however, the role of Akt has also been studied using the pan Akt inhibitor MK-2206, which significantly inhibited human platelet activation induced by various agonists [35]. In the present study, MK-2206 clearly reduced NF- $\mathrm{kB}$ activation, and BAY11-7082 also markedly diminished Akt phosphorylation, suggesting that the signals of NF- $\mathrm{kB}$ and Akt are mutually activated after collagen stimulation in human platelets and that those signals participate critically in the antiplatelet effects of PTE. However, we have not ruled out the possibility that other unknown signals are involved in the PTE-mediated inhibition of platelet activation.

Experimental animal models are key in understanding the therapeutic significance of candidate drugs against arterial thrombosis. Mouse models are ideal as they are technically simple, are quick to operate, and are easily reproducible; one example is that of acute pulmonary thromboembolism triggered by ADP, where the platelet aggregation is closely involved in experimental thrombosis. Heparin $(1.5 \mathrm{U} / \mathrm{g})$ was not effective in reducing ADP-induced thrombolic death in mice (data not shown), which indicates that platelet aggregation, rather than fibrin formation, is a critical cause of thromboembolism. In this study, we observed that PTE is more than two times as potent as BAY11-7082 in reducing the mortality of acute pulmonary thromboembolism. Therefore, the therapeutic efficacy of PTE may be regarded as an attractive natural compound against thromboembolic diseases.

\section{Conclusions}

This study presented a distinctive activation pathway between NF-kB and Akt, which exhibited mutual activation involved in PTE-mediated potent antiplatelet activity in human platelets, and thus it can be used as a prophylactic or as a clinical therapeutic agent for CVDs. Because inflammatory reactions are associated with increased platelet activation, inhibiting platelet over activation by hindering NF- $\mathrm{kB}$ signaling could also be regarded as a novel therapeutic strategy for treating numerous inflammation-related diseases.

Author Contributions: C.-W.H., C.-H.Y., and J.-R.S. conducted experimental work and made the draft; C.-H.H. and W.-C.H. were partially involved in the experiments; T.J. and P.S.B. were partially involved in the experiments and data analysis; K.-R.C. conceived the study and planned the research work. All authors have read and agreed to the published version of the manuscript.

Funding: The Ministry of Science and Technology of Taiwan (MOST107-2320-B-038-035-MY2 and MOST108-2320-B-038-031-MY3), Taipei Medical University-Shuang Ho Hospital (107TMU-SHH-06), and Taipei Medical University (DP2-109-21121-01-N-08-03) supported grants for this work.

Institutional Review Board Statement: This study was approved by the Institutional Review Board of Taipei Medical University (TMU-N201812024) and conformed to the directives of the Declaration of Helsinki. All animal experiments and care procedures conformed to the Guide for the Care and Use of Laboratory Animals (LAC-2019-0365) and were approved by the Institutional Animal Care and Use Committee of Taipei Medical University.

Informed Consent Statement: Informed consent was obtained from all subjects involved in the study.

Data Availability Statement: All data generated or analyzed during this study are included in this published article. 
Conflicts of Interest: The authors declare no conflict of interest.

\section{References}

1. Kojok, K.; El-Kadiry, A.E.; Merhi, Y. Role of NF-кB in platelet function. Int. J. Mol. Sci. 2019, 20, 4185. [CrossRef]

2. Cheng, H.S.; Sivachandran, N.; Lau, A.; Boudreau, E.; Zhao, J.L.; Baltimore, D.; Delgado-Olguin, P.; Cybulsky, M.I.; Fish, J.E. MicroRNA146 represses endothelial activation by inhibiting pro-inflammatory pathways. EMBO Mol. Med. 2013, 5, 949-966. [CrossRef]

3. Gawaz, M.; Langer, H.; May, A.E. May platelets in inflammation and atherogenesis. J. Clin. Investig. 2005, 115, 3378-3384. [CrossRef]

4. Penz, S.; Reininger, A.J.; Brandl, R.; Goyal, P.; Rabie, T.; Bernlochner, I.; Rother, E.; Goetz, C.; Engelmann, B.; Smethurst, P.A.; et al. Human atheromatous plaques stimulate thrombus formation by activating platelet glycoprotein VI. FASEB J. 2005, 19, 898-909. [CrossRef]

5. Tedgui, A.; Mallat, Z. Cytokines in atherosclerosis: Pathogenic and regulatory pathways. Physiol. Rev. 2006, 86, 515-581. [CrossRef]

6. Monaco, C.; Andreakos, E.; Kiriakidis, S.; Mauri, C.; Bicknell, C.; Foxwell, B.; Cheshire, N.; Paleolog, E.; Feldmann, M. Canonical pathway of nuclear factor kappa B activation selectively regulates proinflammatory and prothrombotic responses in human atherosclerosis. Proc. Natl. Acad. Sci. USA 2004, 101, 5634-5639. [CrossRef]

7. Fuentes, E.; Rojas, A.; Palomo, I. NF-кB signaling pathway as target for antiplatelet activity. Blood Rev. 2016, 30, 309-315. [CrossRef] [PubMed]

8. Karim, Z.A.; Zhang, J.; Banerjee, M.; Chicka, M.C.; Al Hawas, R.; Hamilton, T.R.; Roche, P.A.; Whiteheart, S.W. IkappaB kinase phosphorylation of SNAP-23 controls platelet secretion. Blood 2013, 121, 4567-4574. [CrossRef] [PubMed]

9. Rivadeneyra, L.; Carestia, A.; Etulain, J.; Pozner, R.G.; Fondevila, C.; Negrotto, S.; Schattner, M. Regulation of platelet responses triggered by Toll-like receptor 2 and 4 ligands is another non-genomic role of nuclear factor-kappaB. Thromb. Res. 2014, 133, 235-243. [CrossRef]

10. Jackson, S.P.; Yap, C.L.; Anderson, K.E. Phosphoinositide 3-kinases and the regulation of platelet function. Biochem. Soc. Trans. 2004, 32, 387-392. [CrossRef] [PubMed]

11. Kim, S.; Mangin, P.; Dangelmaier, C.; Lillian, R.; Jackson, S.P.; Daniel, J.L.; Kunapuli, S.P. Role of phosphoinositide 3-kinase beta in glycoprotein VI-mediated Akt activation in platelets. J. Biol. Chem. 2009, 284, 33763-33772. [CrossRef]

12. Xiang, B.; Zhang, G.; Liu, J.; Morris, A.J.; Smyth, S.S.; Gartner, T.K.; Li, Z. A G(i)-independent mechanism mediating Akt phosphorylation in platelets. J. Thromb. Haemost. 2010, 8, 2032-2041. [CrossRef]

13. Dvorakova, M.; Landa, P. Anti-inflammatory activity of natural stilbenoids: A review. Pharmacol. Res. 2017, 124, 126-145. [CrossRef]

14. Zhu, Q.; Tang, T.; Liu, H.; Sun, Y.; Wang, X.; Liu, Q.; Yang, L.; Lei, Z.; Huang, Z.; Chen, Z.; et al. Pterostilbene attenuates cocultured BV-2 microglial inflammation-mediated SH-SY5Y neuronal oxidative injury via SIRT-1 signaling. Oxid. Med. Cell. Longev. 2020, 2020, 3986348. [CrossRef]

15. Park, E.S.; Lim, Y.; Hong, J.T.; Yoo, H.S.; Lee, C.K.; Pyo, M.Y.; Yun, Y.P. Pterostilbene, a natural dimethylated analog of resveratrol, inhibits rat aortic vascular smooth muscle cell proliferation by blocking Akt-dependent pathway. Vascular Pharmacol. 2010, 53, 61-67. [CrossRef]

16. Huang, W.C.; Liu, J.C.; Hsia, C.W.; Fong, T.H.; Hsia, C.H.; Tran, O.T.; Velusamy, M.; Yang, C.H.; Sheu, J.R. Pterostilbene, a dimethylether analogue of resveratrol, possesses high potency in the prevention of platelet activation in humans and the reduction of vascular thrombosis in mice. J. Agric. Food Chem. 2021, 69, 4697-4707. [CrossRef]

17. Huang, W.C.; Lin, K.C.; Hsia, C.W.; Hsia, C.H.; Chen, T.Y.; Bhavan, P.S.; Sheu, J.R.; Hou, S.M. The antithrombotic agent pterostilbene interferes with integrin $\alpha_{\mathrm{IIb}} \beta_{3}$-mediated inside-out and outside-in signals in human platelets. Int. J. Mol. Sci. 2021, 22, 3643. [CrossRef] [PubMed]

18. Chen, W.F.; Lee, J.J.; Chang, C.C.; Lin, K.H.; Wang, S.H.; Sheu, J.R. Platelet protease-activated receptor (PAR)4, but not PAR1, associated with neutral sphingomyelinase responsible for thrombin-stimulated ceramide-NF- $\mathrm{K}$ signaling in human platelets. Haematologica 2013, 98, 793-801. [CrossRef] [PubMed]

19. Crosby, D.; Poole, A.W. Physical and functional interaction between protein kinase $C \gamma$ and Fyn tyrosine kinase in human platelets. J. Biol. Chem. 2003, 278, 24533-24541. [CrossRef] [PubMed]

20. Sheu, J.R.; Hung, W.C.; Wu, C.H.; Lee, Y.M.; Yen, M.H. Antithrombotic effect of rutaecarpine, an alkaloid isolated from Evodia rutaecarpa, on platelet plug formation in in vivo experiments. Br. J. Haematol. 2000, 110, 110-115. [CrossRef] [PubMed]

21. Hsia, C.W.; Wu, M.P.; Shen, M.Y.; Hsia, C.H.; Chung, C.L.; Sheu, J.R. Regulation of human platelet activation and prevention of arterial thrombosis in mice by auraptene through inhibition of NF-kB pathway. Int. J. Mol. Sci. 2020, 21, 4810. [CrossRef]

22. Lin, Y.; Bai, L.; Chen, W.; Xu, S. The NF-kappaB activation pathways, emerging molecular targets for cancer prevention and therapy. Expert Opin. Ther. Targets 2010, 14, 45-55. [CrossRef]

23. Swinney, D.C.; Xu, Y.Z.; Scarafia, L.E.; Lee, I.; Mak, A.Y.; Gan, Q.F.; Ramesha, C.S.; Mulkins, M.A.; Dunn, J.; So, O.Y.; et al. A small molecule ubiquitination inhibitor blocks NF-kappa B-dependent cytokine expression in cells and rats. J. Biol. Chem. 2002, 277, 23573-23581. [CrossRef] [PubMed]

24. Ghosh, S.; Hayden, M.S. New regulators of NF-kappaB in inflammation. Nat. Rev. Immunol. 2008, 8, 837-848. [CrossRef] [PubMed]

25. Manning, B.D.; Cantley, L.C. AKT/PKB signaling: Navigating downstream. Cell 2007, 129, 1261-1274. [CrossRef]

26. Fulda, S.; Debatin, K.M. Resveratrol modulation of signal transduction in apoptosis and cell survival: A mini-review. Cancer Detect. Prev. 2006, 30, 217-223. [CrossRef] 
27. Lin, H.S.; Yue, B.D.; Ho, P.C. Determination of pterostilbene in rat plasma by a simple HPLC-UV method and its application in pre-clinical pharmacokinetic study. Biomed. Chromatogr. 2009, 23, 1308-1315. [CrossRef]

28. Kapetanovic, I.M.; Muzzio, M.; Huang, Z.; Thompson, T.N.; McCormick, D.L. Pharmacokinetics, oral bioavailability, and metabolic profile of resveratrol and its dimethylether analog, pterostilbene, in rats. Cancer Chemother. Pharmacol. 2011, 68, 593-601. [CrossRef] [PubMed]

29. Ali, F.Y.; Davidson, S.J.; Moraes, L.A.; Traves, S.L.; Paul-Clark, M.; Bishop-Bailey, D.; Warner, T.D.; Mitchell, J.A. Role of nuclear receptor signaling in platelets: Antithrombotic effects of PPARbeta. FASEB J. 2006, 20, 326-328. [CrossRef] [PubMed]

30. Beaulieu, L.M.; Freedman, J.E. NFkappaB regulation of platelet function: No nucleus, no genes, no problem? J. Thromb. Haemost. 2009, 7, 1329-1332. [CrossRef]

31. Malaver, E.; Romaniuk, M.A.; D’Atri, L.P.; Pozner, R.G.; Negrotto, S.; Benzadon, R.; Schattner, M. NF-kappaB inhibitors impair platelet activation responses. J. Thromb. Haemost. 2009, 7, 1333-1343. [CrossRef] [PubMed]

32. Chen, J.; De, S.; Damron, D.S.; Chen, W.S.; Hay, N.; Byzova, T.V. Impaired platelet responses to thrombin and collagen in AKT-1-deficient mice. Blood 2004, 104, 1703-1710. [CrossRef] [PubMed]

33. Stojanovic, A.; Marjanovic, J.A.; Brovkovych, V.M.; Peng, X.; Hay, N.; Skidgel, R.A.; Du, X. A phosphoinositide 3-kinase-AKTnitric oxide-cGMP signaling pathway in stimulating platelet secretion and aggregation. J. Biol. Chem. 2006, 281, 16333-16339. [CrossRef] [PubMed]

34. O'Brien, K.A.; Stojanovic-Terpo, A.; Hay, N.; Du, X. An important role for Akt3 in platelet activation and thrombosis. Blood 2011, 118, 4215-4223. [CrossRef]

35. Moore, S.F.; van den Bosch, M.T.; Hunter, R.W.; Sakamoto, K.; Poole, A.W.; Hers, I. Dual regulation of glycogen synthase kinase 3 (GSK3)alpha/beta by protein kinase C (PKC)alpha and Akt promotes thrombin-mediated integrin alphaIlbbeta3 activation and granule secretion in platelet. J. Biol. Chem. 2013, 288, 3918-3928. [CrossRef] 